\title{
Prevalence and Risk Factors of Bovine Tuberculosis in Cattle and Dairy Farm Workers in Mirpurkhas and Badin Districts of Sindh, Pakistan
}

\author{
Muhammad Qasim Mazari', Dildar Hussain Kalhoro ${ }^{1, *}$, Hasina Baloch ${ }^{1}$, \\ Muhammad Saleem Kalhoro ${ }^{2}$, Shahid Hussain Abro ${ }^{1}$, Rehana Buriro ${ }^{1}$, Asmatullah Kaka ${ }^{1}$, \\ Fahmida Parveen ${ }^{1}$, Mazhar Hussain Mangi ${ }^{3}$, Ghulam Murtaza Lochi' ${ }^{1}$, Abdul Ahad Soomro ${ }^{4}$, \\ Ali Gul Soomro ${ }^{1}$, Abdul Ghaffar Abbasi ${ }^{1}$ and Sarfraz Hussain Depar ${ }^{1}$ \\ ${ }^{1}$ Departmnent of Veterinary Microbiology, Faculty of Animal Husbandry and Veterinary \\ Sciences, Sindh Agriculture University, Tandojam-70060, Pakistan \\ ${ }^{2}$ Department of Animal Products Technology, Faculty of Animal Husbandry and \\ Veterinary Sciences, Sindh Agriculture University, Tandojam-70060 \\ ${ }^{3}$ Laboratory of Animal Pathology and Public Health, Key Laboratory of Zoonosis, \\ Ministry of Agriculture, College of Veterinary Medicine, China Agriculture University, \\ Beijing, China. \\ ${ }^{4}$ Central Veterinary Diagnostic Laboratory, Tandojam, Sindh, Pakistan
}

\section{A B S T R A C T}

During present study a total of 800 samples were collected from two hundred descriptive (Holstein Friesian) and non-descriptive (Thari) cattle breeds from districts of Mirpurkhas and Badin, 400 samples were taken from each district. Animals were first screened through Single Intradermal Tuberculin Test (SITT) then positive and negative reactors of SITT were further investigated through Rapid BTB Ab test, culture examination and ELISA test. Risk factors such as sex, age, health status, lactating, nonlactating and breed were also investigated. In district Mirpurkhas prevalence was $4 \%, 15 \%, 2 \%, 1 \%$, while in district Badin it was $5 \%, 18 \%, 3 \%, 2 \%$ through SITT, Rapid BTB Ab test, culture examination and ELISA test, respectively. Prevalence of bovine tuberculosis in Mirpurkhas district via cultural examination was recorded as $1.66 \%, 2.5 \%$ in milk and nasal samples, while in district Badin it was $1.66 \%$, $5 \%$, respectively. The overall prevalence of bovine tuberculosis was $5.5 \%$ and $7 \%$ in Mirpurkhas and Badin districts through tuberculin, Rapid BTB Ab, Culture examination and ELISA test. Different tests such as SITT, Rapid BTB Ab, culture examination and ELISA test showed that the prevalence of bovine tuberculosis was higher in females, animals above the six years of age, lactating animals, descriptive breed and animals having poor health status. Furthermore, $1 \%$ and $2 \%$ prevalence was recorded in farm workers at district Mirpurkhas and Badin. It is concluded that disease was prevalent in both districts however; relatively higher prevalence was observed in district Badin.

\begin{tabular}{l} 
Article Information \\
Received 15 September 2019 \\
Revised 17 March 2020 \\
Accepted 10 November 2020 \\
Available online 18 May 2021 \\
(early access) \\
Published 15 February 2022 \\
Authors' Contribution \\
\hline MQM, DHK and HB conceived and \\
designed the experiments. MQM and \\
DH performed the experiments. SHA, \\
RB, AK, FP, MHM, GML and AGS \\
analyzed the data. DHK, MQM and \\
AAS wrote the paper. AGA and SHP \\
checked the references. \\
Key words \\
Prevalence, Cattle, Mirpurkhas, Badin \\
Tubercullosis
\end{tabular}

\section{INTRODUCTION}

$\mathrm{B}$ ovine tuberculosis is one of the important chronic diseases, which produce major economic losses and huge public health threats causing $10-25 \%$ loss in product efficiency in dairy cattle. It is a chronic disease occurs in wild species and domestic animals, after the exposure of disease host can survive for several months, even years without showing clinical signs (De-Lisle et al., 2002). The disease has been associated within the "list-B" disease of

\footnotetext{
Corresponding author: drdildarkalhoro@gmail.com 0030-9923/2022/0003-1115 \$ 9.00/0

Copyright 2022 Zoological Society of Pakistan
}

Office International-des-Epizooties (OIE) (OIE, 2009). The WHO has classified it as one of the seventh zoonotic disease, having a potential of infecting human beings (Malama et al., 2013). There are three important types of tuberculosis i.e. Human tuberculosis affecting humans, avian tuberculosis affecting birds and Bovine tuberculosis affecting human's, cattle and buffalo. Human tuberculosis is rarely transferable to animal species and avian tuberculosis is restricted to the birds, whereas, bovine tuberculosis having zoonotic potential, is highly infectious disease affecting diverse group of animals including farm animals, wild life and humans (Katale et al., 2013). Mycobacterium bovis is a gram positive, acid fast, aerobic, filamentous and curved rod shaped bacteria. It is very slow 
growing bacteria, having generation time of $16 \mathrm{~h}$, that's why it takes months even years to produce infection in their host (Buddle et al., 2006). Carrier animals show important role in transfer of disease to healthy animals, infective dose through inhalation is very low. Infection can be transferred through short distances about 1-2 meters (AHA, 2009). Clinical signs are emaciation, dyspnea, weakness, variable pyrexia, enlargement of lymph nodes and in advance tuberculosis coughing (Peters, 2010). M. bovis infection is transfer to cattle by the inhalation of infectious aerosol, ingestion of contaminated feed, drinking of infected milk. Lesions are associated in upper and lower respiratory tract and lymph nodes (Donnelly and Nouvellet, 2013). Moreover, herds with a better tendency of animal's movement have a great role in disease spreading. Primary route of disease transmission in between herds is the sanitary, poor husbandry, herd size and infected animals (Belchior et al., 2016). There are so many diagnostic techniques such as Enzyme Linked Immunosorbent Assay (ELISA), culture, biochemical, gamma interferon, postmortem, microscopic and tuberculin tests used for the diagnose the Bovine tuberculosis in animals (OIE, 2009). From the milk and saliva samples, diagnosis of $M$. bovis on cultural examination (Lowenstein Jensen agar), Zeheil Nelson staining, microscopic examination and biochemical tests such as Nitrate reduction test, niacin production, urease and tolerance tests are also useful for detection of the organism (OIE, 2004).

Several studies have been reported the prevalence of tuberculosis in large and small ruminants (Ashfaq et al., 2015). Prevalence of bovine tuberculosis in cattle in Punjab was recorded as $1.7 \%$ in buffaloes and $5.1 \%$ in cattle (Ifrahim, 2001). Higher prevalence of bovine tuberculosis from nasal secretions (12.28\%) and milk samples $(28.07 \%)$ from buffaloes were reported (Jalil et al., 2003). Prevalence of bovine tuberculosis in Punjab recorded as 3\% in 2010 (Javed et al., 2010). Though the disease is nearly eliminated in many countries including Slovakia, Sweden, Australia and Canada, it is widespread in Asia, Africa and some Middle East countries (Schiller et al., 2010). According to the World Organization for Animal Health, Turkey is one of the countries where tuberculosis is still present where infection rate in the year 2011 was reported as $22.8 \%$ in cattle population (OIE, 2011). Prevalence of bovine tuberculosis in cattle have not been studied in Mirpurkhas and Badin districts, therefore, the current study is designed to evaluate the prevalence of bovine tuberculosis in dairy farms of Mirpurkhas and Badin districts of Sindh Pakistan. Moreover, risk factors associated with the prevalence of disease was also examined.

\section{MATERIALS AND METHODS}

During present study a total of 800 samples were collected from two hundred descriptive (Holstein Friesian) and non descriptive (Thari) cattle breeds from districts of Mirpurkhas and Badin, 400 samples were taken from each district. The animals were first screened through Single Intradermal Tuberculin Test (SITT) then both positive and negative reactors of SITT were further investigated through Rapid BTB Ab test and culture examinations and ELISA test. Risk factors such as sex, age, health status, lactating, non-lactating and breed were also investigated.

\section{Single intradermal tuberculin test (SITT)}

Centre of the cattle neck was shaved and cleaned with a cotton wool swab (70\% alcohol). A fold of skin was pinched with fingers and thickness was measured with the help of Vernier caliper. Avian tuberculin $(0.1 \mathrm{ml})$ and mammalian $(0.1 \mathrm{ml})$ were injected intradermally at both sides of neck. Injection sites were marked by circle. After $72 \mathrm{~h}$ of post inoculation, result was recorded by measuring the thickness of skin. $4 \mathrm{~mm}$ or more than 4 in the thickness of skin was considered as positive.

\section{Tuberculin skin test in farm workers}

Two hundred farm workers were selected for tuberculin skin test from both districts.

\section{Rapid BTB Ab test}

Serum samples were analyzed by rapid BTB Ab test using commercial kit (Lilli Rapid BTB Ab Test Kit by "Lilly dale Diagnostics" England). One drop of serum was transfered into the sample hole "S" and immediately two drops of assay buffer was added. Results were interpreted after 15-20 min (OIE, 2008).

\section{Enzyme linked immunosorbent assay}

ELISA is known to be most suitable technique for the detection of antibody (Sayin and Erganis, 2013). In the present study AniGen BTB Ab ELISA 2.0 kit was used. Two hundred blood samples were collected from Mirpurkhas and Badin districts for ELISA test.

\section{Milk samples}

The milk samples were collected in sterile bijoux bottles, transferred in ice box and stored at $4^{\circ} \mathrm{C}$. Supernatants were discarded after the centrifugation at $3000 \mathrm{rpm}$ for $15 \mathrm{~min}$. Sediments were used for culture as well as microscopy.

\section{Nasal discharge}

The nasal samples were collected from both districts with sterile cotton swabs in screw caped test tubes and 
stored at $4^{\circ} \mathrm{C}$. Same amount of $\mathrm{NaOH}$ and $\mathrm{N}$-acetyl was mixed with samples and incubated for $30 \mathrm{~min}$ at $37^{\circ} \mathrm{C}$. After centrifugation for $15 \mathrm{~min}$ at $3000 \mathrm{rpm}$, supernatants were discarded. Sediments were used for culture as well as microscopy.

\section{Media for mycobacteria}

Lowenstein Jensen medium was mixed with $1 \%$ of sodium pyruvate and used for bacteriological culture. Thick inoculum of sediments was smeared on the surface medium slopes and incubated at $37^{\circ} \mathrm{C}$ for $6-8$ weeks. Finally, niacin production and urease tests were performed for confirmation. Zeihl Nelson stain was used for the staining of Mycobacterium.

\section{RESULTS AND DISCUSSION}

Prevalence of bovine tuberculosis in Mirpurkhas district was recorded as 4\%,15\%,2\% and $1 \%$ through SITT, rapid BTB Ab, culture examinations and ELISA test, respectively. While in district Badin it was 5\%,18\%, 3\% and $2 \%$ through SITT, rapid BTB Ab, culture examinations and ELISA test, respectively. Overall prevalence of bovine tuberculosis in Mirpurkhas and Badin districts were recorded through SITT, rapid BTB Ab test, Culture examinations and ELISA test $5.5 \%$ and $7 \%$, respectively as shown in Table I.

Table I. The overall prevalence of bovine tuberculosis in cattle at Mirpurkhas and Badin districts analyzed through different techniques.

\begin{tabular}{llllll}
\hline Type of test & \multicolumn{2}{c}{$\begin{array}{c}\text { Mirpurkhas } \\
\text { district }\end{array}$} & & \multicolumn{2}{c}{ Badin district } \\
\cline { 2 - 3 } \cline { 5 - 6 } & $\begin{array}{l}\text { Total } \\
\text { sample }\end{array}$ & Positive & & $\begin{array}{l}\text { Total } \\
\text { sample }\end{array}$ & Positive \\
\hline Tuberculin test (SITT) & 100 & 04 & & 100 & 05 \\
Rapid BTB Ab test & 100 & 15 & & 100 & 18 \\
Culture & 100 & 02 & & 100 & 03 \\
ELISA & 100 & 01 & & 100 & 02 \\
Total & 400 & 22 & & 400 & 28 \\
\hline
\end{tabular}

Prevalence of bovine tuberculosis in Mirpurkhas district via tuberculin test (SITT) was recorded as $4.44 \%$ in female and $0 \%$ in male, while, in district Badin it was $5.55 \%$ in female and $0 \%$ in male. Prevalence of disease in Mirpurkhas district via SITT was recorded as $6.66 \%$, $2.22 \%$ and $0 \%$ in above 6 years, $2-6$ years and less than 2 years of age, respectively, while in district Badin it was $6.66 \%, 4.44 \%$ and $0 \%$ in above 6 years, 2-6 years and less than 2 years of age, respectively. Prevalence of disease in Mirpurkhas district through SITT was recorded as $6.66 \%, 2.85 \%$ and $0 \%$ in poor, satisfactory and good health condition, respectively, while in district Badin it was $8.88 \%, 2.85 \%$ and $0 \%$ in poor, satisfactory and good health conditions, respectively. Prevalence of bovine tuberculosis in Mirpurkhas district via SITT was recorded as 5\%, 3.33\% in lactating non-lactating animals, respectively, while in district Badin it was 6.66\%, 3.33\% in lactating and non-lactating animals, respectively. Prevalence of bovine tuberculosis in Mirpurkhas district via SITT was recorded as $6 \%, 2 \%$, in descriptive (Holstein Friesian) and non-descriptive (Thari) breeds of cattle, respectively, while in district Badin it was $6 \%, 4 \%$ in descriptive (Holstein Friesian) and non-descriptive (Thari) breeds of cattle, respectively Table II.

Table II. Prevalence of bovine tuberculosis in cattle population of districts of Mirpurkhas and Badin in association of risk factors such as sex, age, health status, lactation and breed SITT.

\begin{tabular}{|c|c|c|c|c|}
\hline \multirow[t]{3}{*}{ Risk factors } & \multicolumn{2}{|c|}{ District Mipurkhas } & \multicolumn{2}{|c|}{ District Badin } \\
\hline & \multirow[t]{2}{*}{ Total } & $\begin{array}{l}\text { Tuberculin } \\
\text { test (SITT) }\end{array}$ & \multirow[t]{2}{*}{ Total } & \multirow{2}{*}{$\begin{array}{l}\begin{array}{l}\text { Tuberculin } \\
\text { test (SITT) }\end{array} \\
\text { Positive (\%) }\end{array}$} \\
\hline & & Positive (\%) & & \\
\hline \multicolumn{5}{|l|}{ Sex } \\
\hline Female & 90 & $04(4.44 \%)$ & 90 & $05(5.55 \%)$ \\
\hline Male & 10 & $00(0 \%)$ & 10 & $00(00 \%)$ \\
\hline Total & 100 & $04(4 \%)$ & 100 & $05(05 \%)$ \\
\hline \multicolumn{5}{|l|}{ Age } \\
\hline$\leq 2$ years & 10 & $00(0 \%)$ & 10 & $00(00 \%)$ \\
\hline Above 2 to 6 years & 45 & $01(2.22 \%)$ & 45 & $02(4.44 \%)$ \\
\hline$>6$ years & 45 & $03(6.66 \%)$ & 45 & $03(6.66 \%)$ \\
\hline Total & 100 & $04(4 \%)$ & 100 & $05(05 \%)$ \\
\hline \multicolumn{5}{|l|}{ Health status } \\
\hline Poor & 45 & $3(6.66 \%)$ & 45 & $4(8.88 \%)$ \\
\hline Satisfactory & 35 & $01(2.85 \%)$ & 35 & $01(2.85 \%)$ \\
\hline Good & 20 & $00(0 \%)$ & 20 & $00(00 \%)$ \\
\hline Total & 100 & $04(4 \%)$ & 100 & $05(05 \%)$ \\
\hline Lactating & 60 & $03(5 \%)$ & 60 & $04(6.66 \%)$ \\
\hline Non-lactating & 30 & $01(3.33 \%)$ & 30 & $01(3.33 \%)$ \\
\hline Total & 90 & $04(4.44 \%)$ & 90 & $05(5.55 \%)$ \\
\hline \multicolumn{5}{|l|}{ Breed } \\
\hline Descriptive (HF) & 50 & $03(06 \%)$ & 50 & $03(06 \%)$ \\
\hline $\begin{array}{l}\text { Non- descriptive } \\
\text { (Thari) }\end{array}$ & 50 & $01(02 \%)$ & 50 & $02(04 \%)$ \\
\hline Total & 100 & $04(04 \%)$ & 100 & $05(05 \%)$ \\
\hline
\end{tabular}

Prevalence of bovine tuberculosis in Mirpurkhas district via rapid BTB Ab test was recorded as $15.55 \%$ in female and $10 \%$ in male, while in district Badin it was 
Table III. Prevalence of bovine tuberculosis in cattle population of districts of Mirpurkhas and Badin in association of risk factors such as sex, age, health status, lactation and breed through Rapid BTB Ab test.

\begin{tabular}{|c|c|c|c|c|}
\hline \multirow[t]{3}{*}{ Risk factors } & \multicolumn{2}{|c|}{ District Mipurkhas } & \multicolumn{2}{|c|}{ District Badin } \\
\hline & \multirow[t]{2}{*}{ Total } & $\begin{array}{l}\text { Rapid } \\
\text { BTB Ab }\end{array}$ & \multirow[t]{2}{*}{ Total } & \multirow{2}{*}{$\begin{array}{l}\text { Rapid } \\
\text { BTB Ab } \\
\text { Positive (\%) }\end{array}$} \\
\hline & & $\overline{\text { Positive (\%) }}$ & & \\
\hline \multicolumn{5}{|l|}{ Sex } \\
\hline Female & 90 & $14(15.55 \%)$ & 90 & $17(18.88 \%)$ \\
\hline Male & 10 & $01(10 \%)$ & 10 & $01(10 \%)$ \\
\hline Total & 100 & $15(15 \%)$ & 100 & $18(18 \%)$ \\
\hline \multicolumn{5}{|l|}{ Age } \\
\hline$\leq 2$ years & 10 & $01(10 \%)$ & 10 & $00(00 \%)$ \\
\hline Above 2 to 6 years & 45 & $06(13.33 \%)$ & 45 & $08(17.77 \%)$ \\
\hline$>6$ years & 45 & $08(17.77 \%)$ & 45 & $10(22.22 \%)$ \\
\hline Total & 100 & $15(15 \%)$ & 100 & $18(18 \%)$ \\
\hline \multicolumn{5}{|l|}{ Health status } \\
\hline Poor & 45 & $09(20 \%)$ & 45 & $11(24.44 \%)$ \\
\hline Satisfactory & 35 & $05(14.28 \%)$ & 35 & $07(20 \%)$ \\
\hline Good & 20 & $01(5 \%)$ & 20 & $00(00 \%)$ \\
\hline Total & 100 & $15(15 \%)$ & 100 & $18(18 \%)$ \\
\hline Lactating & 60 & $11(18.33 \%)$ & 60 & $13(21.66 \%)$ \\
\hline Non-lactating & 30 & $03(10 \%)$ & 30 & $04(13.33 \%)$ \\
\hline Total & 90 & $14(15.55 \%)$ & 90 & $17(18.88 \%)$ \\
\hline \multicolumn{5}{|l|}{ Breed } \\
\hline Descriptive (HF) & 50 & $08(16 \%)$ & 50 & $10(20 \%)$ \\
\hline $\begin{array}{l}\text { Non- descriptive } \\
\text { (Thari) }\end{array}$ & 50 & $07(14 \%)$ & 50 & $08(16 \%)$ \\
\hline Total & 100 & $15(15 \%)$ & 100 & $18(18 \%)$ \\
\hline
\end{tabular}

$18.88 \%$ in female and $10 \%$ in male animals, respectively. Prevalence of disease in Mirpurkhas district via rapid BTB Ab test was recorded as $17.77 \%, 13.33 \%$ and $10 \%$ in above 6 years, 2-6 years and less than 2 years of age, respectively, while in district Badin it was $22.22 \%, 17.77 \%$ and $0 \%$ in above 6 years, 2-6 years and less than 2 years of age, respectively. Prevalence of bovine tuberculosis in Mirpurkhas district via rapid BTB Ab test was recorded as $20 \%, 14.28 \%$ and $5 \%$ in poor, satisfactory and good health condition, respectively, while in district Badin it was $24.44 \%, 20 \%$ and $0 \%$ in poor, satisfactory and good health condition animals, respectively. Prevalence of bovine tuberculosis in Mirpurkhas district via rapid BTB $\mathrm{Ab}$ test was recorded as $18.33 \%, 10 \%$ in lactating and non-lactating animals, respectively, while in district Badin it was $21.66 \%, 13.33 \%$ in lactating and non-lactating animals, respectively. Prevalence of disease in Mirpurkhas district via rapid BTB Ab test was recorded as $16 \%, 14 \%$, in descriptive (Holstein Friesian) and non-descriptive (Thari) breeds of cattle, respectively, while in district Badin it was 20\%, 16\%, in descriptive (Holstein Friesian) non-descriptive (Thari) breeds of cattle, respectively as summarized in Table III. Prevalence of bovine tuberculosis in Mirpurkhas district through cultural examination was recorded as $1.66 \%, 2.5 \%$ in milk and nasal samples, respectively, while in district Badin it was $1.66 \%, 5 \%$ in milk and nasal samples, respectively as shown in Table IV.

Table IV. Prevalence of bovine tuberculosis in cattle at Mirpurkhas and Badin districts by culture examination.

\begin{tabular}{|c|c|c|c|c|}
\hline \multirow{2}{*}{$\begin{array}{l}\text { Source of } \\
\text { sample }\end{array}$} & \multicolumn{2}{|c|}{ District Mipurkhas } & \multicolumn{2}{|c|}{ District Badin } \\
\hline & $\begin{array}{l}\text { No of } \\
\text { sample }\end{array}$ & $\begin{array}{l}\text { Positive } \\
(\%)\end{array}$ & $\begin{array}{l}\text { No of } \\
\text { sample }\end{array}$ & $\begin{array}{l}\text { Positive } \\
\text { (\%) }\end{array}$ \\
\hline Milk & 60 & $01(1.66 \%)$ & 60 & $01(1.66 \%)$ \\
\hline Nasal swab & 40 & $01(2.5 \%)$ & 40 & $02(5 \%)$ \\
\hline Total & 100 & $02(2 \%)$ & 100 & $03(3 \%)$ \\
\hline
\end{tabular}

Table V. Prevalence of bovine tuberculosis among cattle at Mirpurkhas and Badin Districts in relation to the various risk factors such as sex, age, health status, lactation and breed analyzed by culture examination.

\begin{tabular}{|c|c|c|c|c|}
\hline \multirow[t]{3}{*}{ Risk factors } & \multicolumn{2}{|c|}{ District Mipurkhas } & \multicolumn{2}{|c|}{ District Badin } \\
\hline & \multirow[t]{2}{*}{$\overline{\text { Total }}$} & $\begin{array}{l}\text { Culture } \\
\text { examination }\end{array}$ & \multirow[t]{2}{*}{ Total } & \multirow{2}{*}{$\begin{array}{l}\text { Culture } \\
\text { examination } \\
\text { Positive (\%) }\end{array}$} \\
\hline & & $\overline{\text { Positive (\%) }}$ & & \\
\hline \multicolumn{5}{|l|}{$\overline{\text { Sex }}$} \\
\hline Female & 90 & $02(2.22 \%)$ & 90 & $03(3.33 \%)$ \\
\hline Male & 10 & $00(0 \%)$ & 10 & $00(0 \%)$ \\
\hline Total & 100 & $02(2 \%)$ & 100 & $03(3 \%)$ \\
\hline \multicolumn{5}{|l|}{ Age (years) } \\
\hline$\leq 2$ & 10 & $00(0 \%)$ & 10 & 00 \\
\hline Above 2 to 6 years & 45 & $00(0 \%)$ & 45 & $00(0 \%)$ \\
\hline$>6$ years & 45 & $02(4.44 \%)$ & 45 & $03(6.66 \%)$ \\
\hline Total & 100 & $02(2 \%)$ & 100 & $03(3 \%)$ \\
\hline \multicolumn{5}{|l|}{ Health status } \\
\hline Poor & 45 & $02(4.44 \%)$ & 45 & $03(6.66 \%)$ \\
\hline Satisfactory & 35 & $00(0 \%)$ & 35 & $00(0 \%)$ \\
\hline Good & 20 & $00(0 \%)$ & 20 & $00(0 \%)$ \\
\hline Total & 100 & $02(2 \%)$ & 100 & $03(3 \%)$ \\
\hline Lactating & 60 & $02(3.33 \%)$ & 60 & $03(5 \%)$ \\
\hline Non-lactating & 30 & $00(0 \%)$ & 30 & $00(0 \%)$ \\
\hline Total & 90 & $02(2.22 \%)$ & 90 & $03(3.33 \%)$ \\
\hline \multicolumn{5}{|l|}{ Breed } \\
\hline Descriptive (HF) & 50 & $02(4 \%)$ & 50 & $03(06 \%)$ \\
\hline $\begin{array}{l}\text { Non- descriptive } \\
\text { (Thari) }\end{array}$ & 50 & $00(0 \%)$ & 50 & $00(0 \%)$ \\
\hline Total & 100 & $02(2 \%)$ & 100 & $03(3 \%)$ \\
\hline
\end{tabular}


Table VI. Prevalence of bovine tuberculosis among cattle at Mirpurkhas and Badin Districts in relation to the various risk factors such as sex, age, health status, lactation and breed analyzed by ELISA.

\begin{tabular}{|c|c|c|c|c|}
\hline \multirow[t]{3}{*}{ Risk factors } & \multicolumn{2}{|c|}{ District Mirpurkhas } & \multicolumn{2}{|c|}{ District Badin } \\
\hline & \multirow[t]{2}{*}{ Total } & Elisa test & \multirow[t]{2}{*}{ Total } & \multirow{2}{*}{$\begin{array}{l}\text { Elisa test } \\
\text { Positive (\%) }\end{array}$} \\
\hline & & Positive (\%) & & \\
\hline \multicolumn{5}{|l|}{ Sex } \\
\hline Female & 90 & $01(1.11 \%)$ & 90 & $02(2.22 \%)$ \\
\hline Male & 10 & $0(0 \%)$ & 10 & $00(0 \%)$ \\
\hline Total & 100 & $01(01 \%)$ & 100 & $02(02 \%)$ \\
\hline \multicolumn{5}{|l|}{ Age (years) } \\
\hline$\leq 2$ & 10 & $0(0 \%)$ & 10 & $0(0 \%)$ \\
\hline Above 2 to 6 years & 45 & $0(0 \%)$ & 45 & $0(0 \%)$ \\
\hline$>6$ years & 45 & $01(2.22 \%)$ & 45 & $02(4.44 \%)$ \\
\hline Total & 100 & $01(01 \%)$ & 100 & $02(02 \%)$ \\
\hline \multicolumn{5}{|l|}{ Health status } \\
\hline Poor & 45 & $01(2.22 \%)$ & 45 & $02(4.44 \%)$ \\
\hline Satisfactory & 35 & $00(00 \%)$ & 35 & $0(0 \%)$ \\
\hline Good & 20 & $00(00 \%)$ & 20 & $0(0 \%)$ \\
\hline Total & 100 & $01(01 \%)$ & 100 & $02(02 \%)$ \\
\hline $\begin{array}{l}\text { Lactation } \\
\text { Lactating }\end{array}$ & 30 & $01(3.33 \%)$ & 30 & $02(6.66 \%)$ \\
\hline Non-lactating & 60 & $0(0 \%)$ & 60 & $0(0 \%)$ \\
\hline Total & 90 & $01(1.11 \%)$ & 90 & $02(2.22 \%)$ \\
\hline \multicolumn{5}{|l|}{ Breed } \\
\hline Descriptive & 50 & $01(02 \%)$ & 50 & $02(04 \%)$ \\
\hline Non- descriptive & 50 & $0(0 \%)$ & 50 & $0(0 \%)$ \\
\hline Total & 100 & $1(01 \%)$ & 100 & $02(02 \%)$ \\
\hline
\end{tabular}

Through culture examination prevalence of bovine tuberculosis in Mirpurkhas district was recorded as $2.22 \%$ in female and $0 \%$ in male animals, while in district Badin it was $3.33 \%$ in female and $0 \%$ in male animals, respectively. Prevalence of bovine tuberculosis in Mirpurkhas district via culture examination was recorded as $4.44 \%, 0 \%$ and $0 \%$ in above 6 years, 2-6 years and less than 2 years of age, respectively, while in district Badin it was $6.66 \%, 0 \%$ and $0 \%$ in above 6 years, 2-6 years and less than 2 years of age, respectively. Prevalence of bovine tuberculosis in Mirpurkhas district via culture examination was recorded as $4.44 \%, 0 \%$ and $0 \%$ in poor, satisfactory and good health condition, respectively; while in district Badin it was of $6.66 \%, 0 \%$ and $0 \%$ in poor, satisfactory and good health condition, respectively. Prevalence of bovine tuberculosis in Mirpurkhas district via culture examination was recorded as $3.33 \%, 0 \%$ in lactating and non-lactating animals, respectively, while in district Badin it was 5\%,
$0 \%$ in lactating and non-lactating animals, respectively. Prevalence of bovine tuberculosis in Mirpurkhas district via culture examination was recorded as $4 \%, 0 \%$, in descriptive (Holstein Friesian) and non-descriptive (Thari) breeds of cattle, respectively, while in district Badin it was $6 \%, 0 \%$, descriptive (Holstein Friesian) and nondescriptive (Thari) breeds of cattle, respectively (Table V).

Prevalence of bovine tuberculosis in Mirpurkhas district via ELISA test was recorded as $1.11 \%$ in female and $0 \%$ in male, while in district Badin it was $2.22 \%$ in female and $0 \%$ in male animals, respectively. Prevalence of Bovine tuberculosis in Mirpurkhas district via ELISA test was recorded as $2.22 \%, 0 \%$ and $0 \%$ in above 6 years, $2-6$ years and less than 2 years of age, respectively, while in district Badin it was $4.44 \%, 0 \%$ and $0 \%$ in above 6 years, $2-6$ years and less than 2 years of age, respectively. Prevalence of bovine tuberculosis in Mirpurkhas district via ELISA test was recorded as $2.22 \%, 0 \%$ and $0 \%$ in poor, satisfactory and good health condition, respectively, while in district Badin it was $4.44 \%, 0 \%$ and $0 \%$ in poor, satisfactory and good health condition animals, respectively. Prevalence of bovine tuberculosis in Mirpurkhas district via ELISA test was recorded as $3.33 \%, 0 \%$ in lactating and non-lactating animals, respectively, while in district Badin it was $6.66 \%$, $0 \%$ in lactating and non-lactating animals, respectively. Prevalence of bovine tuberculosis in Mirpurkhas district via ELISA test was recorded as $2 \%, 0 \%$, in descriptive (Holstein Friesian) and non-descriptive (Thari) breeds of cattle, respectively, while in district Badin it was $4 \%, 0 \%$, in descriptive (Holstein Friesian) non-descriptive (Thari) breeds of cattle, respectively (Table VI).

District Badin 100 workers were tested by tuberculin test in which $2 \%$ workers were positive reactor of tuberculin test while in district Mirpurkhas also 100 workers were tested in which $1 \%$ workers were positive reactor of tuberculin test and total prevalence in both district were $1.5 \%$ (Table VII).

Table VII. Prevalence of tuberculosis in cattle owner farmers at Mirpurkhas and Badin districts by Tuberculin test.

\begin{tabular}{lll}
\hline No of worker checked & n & No of positive reactor (\%) \\
\hline Badin & 100 & $02(2 \%)$ \\
Mirpurkhas & 100 & $01(01 \%)$ \\
Total & 200 & $03(1.5 \%)$ \\
\hline
\end{tabular}

\section{DISCUSSION}

During present study a total of 800 samples were collected from two hundred descriptive (Holstein Friesian) 
and non descriptive (Thari) cattle breeds from districts of Mirpurkhas and Badin, 400 samples were taken from each district. Out of 400 samples in Mirpurkhas district 4\%, $15 \% 2 \%$ and $1 \%$ were found positive by (SITT) tuberculin, rapid $\mathrm{BTB} \mathrm{Ab}$, culture examination and ELISA test, respectively, while in Badin district 5\%,18\%,3\% and 2\% were positive against bovine tuberculosis through (SIIT) tuberculin, rapid BTB Ab, culture examination and ELISA test, respectively. The variation in results between tests is because of immune system's sensitivity and specificity towards the tuberculin test in different animals and chronic nature of tested animals (Konch et al., 2017). Present study was designed to detect prevalence of bovine tuberculosis through SITT as 4\%, 5\% in Mirpurkhas and Badin districts, respectively. The findings of the study are in line with the reports of Jalil et al. (2003), who reported 7.3\% prevalence in Lahore. Present findings are lower than findings of Khan et al. (2008), Thakur et al. (2010), Kumar et al. (2013), who reported $12 \%$ prevalence of bovine tuberculosis in Lahore Pakistan, $14.31 \%$ in Himachal Pradesh India, $23.63 \%$ in Punjab area of India through SITT.

Whereas, through rapid BTB Ab test, a positive percentage of $15 \%$ and $18 \%$ was observed in Mirpurkhas and Badin districts. Higher prevalence was recorded through this test as compared to other tests. Our results are comparable with previous findings of Rahman and Samad (2008) and Islam et al. (2007) who reported 30\% prevalence of rapid BTB Ab test, whereas, $2 \%$ and $3 \%$ prevalence were observed in district Mirpurkhas and Badin through culture examinations. Present results are line with the findings of other authors who reported $4.28 \%$ prevalence in Lahore, Pakistan (Qamar and Tehmina, 2013). ELISA was also used to detect prevalence of bovine tuberculosis as $1 \%, 2 \%$ in Mirpurkhas and Badin districts, respectively. Present findings of study agree with the Buyuk et al. (2017) who reported 3\% prevalence of bovine tuberculosis in cattle by ELISA test. However, current findings are lower than findings of Ratan et al. (2018) and Silva (2001) who reported 23.7\% and $47 \%$ prevalence of bovine tuberculosis in cattle through Elisa technique, respectively. Hassanain et al. (2009) reported $50 \%$ prevalence in Egypt. During present study prevalence of bovine tuberculosis indicated that it mostly affects the female as compared to the male in all tests that agrees with previous studies in other laboratories (Noorrahim et al., 2015; Mondal et al., 2014; Buyuk et al., 2017) who reported that females were more effected as compared to male, through all tests. Higher prevalence of the disease may be associated with stress produced from high milk producer animals (Mukherjee, 2006).

Disease prevalence was higher in older animals as compared to the younger animals. Present results are in line with those of Noorrahim et al. (2015), Chandra et al. (2007), Javed et al. (2012) and Ratan et al. (2018) who stated that older animals were more susceptible than younger animal by all tests. Older animals were highly affected due to prolonged closed confinement with positive reactors (Mackay and Hein, 1989). Higher prevalence of bovine tuberculosis was observed in lactating as compared to the non-lactating (dry animals). Current findings are in agreement with those of Arshad et al. (2012), Khan et al. (2008), Sayin and Erganis (2013) and Jalil et al. (2003) who reported that the disease is highly prevalent in lactating than non- lactating animals. It has been suggested that lactating animals are at higher risk due to greater yield (Amin et al., 1992; Rodwell et al., 2001), whereas higher prevalence was observed in HF animals as compared to Thari animals through all tests. Present result are in line with those of Trangadia et al. (2013), Tahmid Uddin et al. (2014), Khan et al. (2008) and Buyuk et al. (2017), who suggested that descriptive breeds were more effected. Higher potential production of HF directly associated with stress therefore, animal active towards disease (Trangadia et al., 2013). Present study was also designed to detect the prevalence of bovine tuberculosis through SITT in humans as $1 \%, 2 \%$ in Mirpurkhas and Badin districts, respectively. The findings of the study are in line with the reports of Muller et al. (2013), who reported $2.8 \%$ prevalence in Africa.

\section{CONCLUSION}

This study reported that prevalence of bovine tuberculosis in both districts, but higher prevalence was observed in Badin as compared to Mirpurkhas district, whereas, bovine tuberculosis cases were higher in female than male animals. Farm workers, Lactating, descriptive breeds, animals with age group of $>6$ years were shown higher rate of infection than young animals. while, higher prevalence was observed through rapid BTB Ab test as compared to other tests.

\section{ACKNOWLEDGEMENTS}

The authors are highly thankful to the Central Veterinary Diagnostic Laboratory, Tandojam, Directorate of Veterinary Research and Diagnosis, Government of Sindh, Pakistan

\section{Statement of conflict of interest}

The authors have no conflict of interest to declare. 


\section{REFERENCES}

Amin, S., Khan, M.A., Hashmi, H.A., Khan, M.S., Ahmad I. and Bhatti, M.A., 1992. Detection of buffalo tuberculosis by using short thermal test and isolation of causal organisms from lymph nodes. Buff. J., 8: 83-7.

Animal Health Australia, 2009. Bovine tuberculosis case response manual, managing an incident of bovine tuberculosis. Tub. Cas. Res. Man. Fin. J., 04-11-09, pp. 1-9.

Arshad, M., Ifrahim, M., Ashraf, M., Rehman, S.U. and Khan, H.A., 2012. Epidemiological studies on tuberculosis in buffalo population in villages around Faisalabad. J. Anim. Pl. Sci., 22: 246-249.

Ashfaq, M., Razzaq, A. and Muhammad, G., 2015. Economic analysis of dairy animal diseases in Punjab: A case study of Faisalabad district. J. Anim. Pl. Sci., 5: 25-35.

Belchior, A.P.C., Lopes, L.B., Goncalves, V.S.P. and Leite, R.C., 2016. Prevalence and risk factors for bovine tuberculosis in Minas Gerais State, Brazil. Trop. Anim. Hlth. Prod., 48: 373-378. https://doi. org/10.1007/s11250-015-0961-x

Buddle, B.M., Wedlock, D.N. and Denis, M., 2006. Progress in the development of tuberculosis vaccines for cattle and wildlife. Vet. Microbiol., 112: 191200. https://doi.org/10.1016/j.vetmic.2005.11.027

Buyuk, F., Bozukluhan, K., Saglam, A.G., Gokce, G., Celebi, O., Celik, E. and Sahin, M., 2017. The prevalence estimates of Mycobacterium bovis infection in cattle with ELISA. J. Hell. Vet. Med. Soc., 68: 541-546. https://doi.org/10.12681/ jhvms. 16050

Chandra, H.A.V., Yukio, M., Dhakal, M., Besnet, B., Sato, T., Nagai, A., Kato, M., Kozawa, K., Yamamoto, S. and Kimura, H., 2007. Isolation of Mycobacterium spp. from milking buffaloes and cattle in Nep. J. Vet. Med. Sci., 69: 819-825. https:// doi.org/10.1292/jvms.69.819

De Lisle, G.W., Bengis, R.G., Schmitt, S.M. and O Brien, D.J., 2002. Tuberculosis in free-ranging wildlife detection, diagnosis and management. Rev. Sci. Tech. OIE., 21: 317-334. https://doi. org/10.20506/rst.21.2.1339

Donnelly, C.A. and Nouvellet, P., 2013. The contribution of badgers to confirmed tuberculosis in cattle in high-incidence areas in England. PLoS Curr, 5: https://doi.org/10.1371/currents. outbreaks.097a904d3f3619db2fe78d24bc776098

Hassanain, N.A., Hassanain, M.A., Soliman, Y.A., Ghazy, A.A. and GhazyI, Y.A., 2009. Bovine tuberculosis in a dairy cattle farm as a threat to public health. Afri. J. Microbiol. Res., 3: 446-450.

Ifrahim, M., 2001. Epidemiological studies on tuberculosis in cattle and buffalo population in villages around Faisalabad. M.Sc. Hons. thesis Department of Veterinary Microbiology, University of Agriculture Faisalabad, Pakistan.

Islam, M.M., Siddique, M.A.R., Haque, M.A., Baki, M.A., Majumder, S., Parrish, J.J. and Shamsuddin, M., 2007. Screening some major communicable diseases of AI bulls in Bangladesh. Livest. Res. Rural Dev., 19: 1-9.

Jalil, H., Das, P. and Suleman, A., 2003. Bovine tuberculosis in dairy animals at Lahore, threat to the public health. Metropolitan Corporation Lahore, Pakistan. pp. 1-11.

Javed, M.T., Ahmad, L., Feliziani, F., Pasquali, P., Akhtar, M., Usman, M. and Cagiola, M., 2012. Analysis of some of the epidemiological risk factors affecting the prevalence of tuberculosis in buffalo at seven livestock farms in Punjab Pakistan. Asian Biomed., 6: 35-42. https://doi.org/10.1016/j. actatropica.2010.04.004

Javed, M.T., Shahid, A.L., Farooqi, F.A., Akhtar, M., Cardenas, G.A., Wasiq, M. and Cagiola, M., 2010. Risk factors associated with the presence of positive reactions in the SCCIT test in water buffalo around two cities in Punjab, Pakistan. Acta Trop., 115: 242247.

Katale, B.Z., Mbugi, E.V., Karimuribo, E.D., Keyyu, J.D., KendalL, S., Kibiki, G.S., Godfrey, P., Faussett, A. L., Michel, R.R., Kazwala, VAN., Helden, P. and Matee, M.I., 2013. Prevalence and risk factors or infection of bovine tuberculosis in indigenous cattle in the Serengeti ecosystem, Tanzania. Vet. Res., 9: 267. https://doi.org/10.1186/1746-6148-9-267

Khan, I.A., Khan, A., Mubarak, A. and Ali, S., 2008. Factors affecting prevalence of bovine tuberculosis in Nili Ram buffaloes. Pak. Vet. J., 1: 28-34.

Konch, P., Dutta, B., Goswami, S., Barua, A.G. and Saikia, G.K.,2017. Prevalence of bovine tuberculosis in Assam India, 5: 143-146.

Kumar, H., Randhawa, S.N.S., Gupta, M.P., Brar, A.P.S., Kaur, K., Filia, G. and Chand, N., 2013. Bovine and caprine tuberculosis in Punjab. Ind. Vet. J., 90: 26-29.

Mackay, C.R. and Hein, W.R., 1989. A large proportion of bovine $\mathrm{T}$ cells express the $\mathrm{T}$ cell receptor and show a distinct tissue distribution and surface phenotype. Int. Immunol, 1: 540-545. https://doi. org/10.1093/intimm/1.5.540

Malama, S., Muma, J.B. and Godfroid, J., 2013. A 
review of tub Infectious diseases of poverty 2.1 erculosis at the wildlife-livestock-human interface in Zambia. pp. 13. https://doi.org/10.1186/20499957-2-13

Mondal, M.A.H., Parvin, M.S., Sarker, S.C., Rahman, A.K.M.A. and Islam, M.T., 2014. Prevalence and risk factors of bovine tuberculosis in cattle in Mymensingh Sadar. Bangladesh J. Vet. Med., 12: 179-183. https://doi.org/10.3329/bjvm. v12i2.21283

Mukherjee, F., 2006. Comparative prevalence of tuberculosis in two dairy herds in India. Rev. Sci. Tech. OIE, 25: 1125-1130. https://doi.org/10.20506/ rst.25.3.1717

Muller, B., Dürr, S., Alonso, S., Hattendorf, J., Laisse, C.J., Parsons, S.D. and Zinsstag, J., 2013. Zoonotic Mycobacterium bovis induced tuberculosis in humans. Emerg. Infect. Dis., 19: 6899. https://doi. org/10.3201/eid1906.120543

Noorrahim, M.S., Shahid, K.M., Shah, A., Shah, M. and Rafiullah, H.A., 2015. Prevalence of tuberculosis in livestock population of district Charsadda by Tuberculin Skin Test (TST). J. Entomol. Zool. Stud., 2: 15-19.

OIE, 2004. Office international des épizooties, 2004. Manual of diagnostic tests and vaccines for terrestrial animals: 2004. OIE.

OIE, 2008. Office international des epizooties terrestrial manual. Chapter 2.4.7, W. H. O.

OIE, 2009. Manual of standards for diagnostic tests and vaccines, Bovine tuberculosis O.I.E, pp. 683-697.

OIE, 2011. World animal health information database. http://www.oie.int/wahis_2/public/wahid.php/ Disease information/statusdetail.

Peters, D., 2010. Farm animals, signs and symptoms of tuberculosis in cattle. UK. pp.1-8.

Qamar, M.F. and Azhar, T., 2013. Detection of Mycobacterium from bovine milk in Lahore, Pakistan. Sci. Int., 25: 2.

Rahman, M.M. and Samad, M.A., 2008. Prevalence of bovine tuberculosis and its effects on milk production in Red Chittagong cattle. Bangladesh
J. Vet. Med., 6: 175-178. https://doi.org/10.3329/ bjvm.v6i2.2332

Ratan Das, Dandapat, P., Chakrabarty, A., Nanda, P.K., Bandyopadhyay, S. and Bandyopadhyay, S., 2018. A cross-sectional study on prevalence of bovine tuberculosis in Indian and crossbred cattle in Gangetic delta region of West Bengal, India. Int. J. One Hlth., 4: 1-7. https://doi.org/10.14202/ IJOH.2018.1-7

Rodwell, T.C., Whyte, I.J. and Boyce, W.M., 2001. Evaluation of population effects of bovine tuberculosis in free-ranging African buffalo (Syncerus caffer). J. Mammal., 82: 231-238. https:// doi.org/10.1644/1545-1542(2001)082<0231:EOP $\mathrm{EOB}>2.0 . \mathrm{CO} ; 2$

Sayin, Z. and Erganis, O., 2013. Diagnosis of bovine tuberculosis by PPD-ELISA and sonicationELISA. Isr. J. Vet. Med., 68: 180-184.

Schiller, I., Oesch, B., Vordermeier, H.M., Palmer, M.V., Harris, B.N., Orloski, K.A., Buddle, B.M., Thacker, T.C., Lyashchenko, K.P. and Waters, W.R., 2010. Bovine tuberculosis. A review of current and emerging diagnostic techniques in view of their relevance for disease control and eradication. Transb. Emerg. Dis., 57: 205-220. https://doi. org/10.1111/j.1865-1682.2010.01148.x

Silva, E., 2001. Evaluation of an enzyme-linked immunosorbent assay in the diagnosis of bovine tuberculosis. Vet. Microbiol., 78: 111-117. https:// doi.org/10.1016/S0378-1135(00)00282-0

Tahmid, A.S.M.T., Akter, M.R., Khatun, M.N., Mannan, M.A., Rahman, M.M. and Kabir, S.L., 2014. Investigation of bovine tuberculosis in rangpur division of Bangladesh. J. Life Sci. Res., 1: 1-4.

Thakur, A., Sharma, M., Katoch, V.C., Dhar, P. and Katoch, R.C., 2010. A study on the prevalence of bovine tuberculosis in farmed dairy cattle in Himachal Pradesh. Vet. World, 3: 409-414. https:// doi.org/10.5455/vetworld.2010.408-413

Trangadia, B.J., Rana, S.K. and Srinivasan, V.A., 2013. Prevalence of bovine tuberculosis in organized dairy farm. Ind. J. Vet. Patthol., 37: 72-74. 